\title{
Whole-cell fungal transformation of precursors into dyes
}

\author{
Jolanta Polak* and Anna Jarosz-Wilkołazka
}

\begin{abstract}
Background: Chemical methods of producing dyes involve extreme temperatures and unsafe toxic compounds. Application of oxidizing enzymes obtained from fungal species, for example laccase, is an alternative to chemical synthesis of dyes. Laccase can be replaced by fungal biomass acting as a whole-cell biocatalyst with properties comparable to the isolated form of the enzyme. The application of the whole-cell system simplifies the transformation process and reduces the time required for its completion. In the present work, four fungal strains with a well-known ability to produce laccase were tested for oxidation of 17 phenolic and non-phenolic precursors into stable and nontoxic dyes.

Results: An agar-plate screening test of the organic precursors was carried out using four fungal strains: Trametes versicolor, Fomes fomentarius, Abortiporus biennis, and Cerrena unicolor. Out of 17 precursors, nine were transformed into coloured substances in the presence of actively growing fungal mycelium. The immobilized fungal biomass catalyzed the transformation of $1 \mathrm{mM}$ benzene and naphthalene derivatives in liquid cultures yielding stable and non-toxic products with good dyeing properties. The type of fungal strain had a large influence on the absorbance of the coloured products obtained after 48-hour transformation of the selected precursors, and the most effective was Fomes fomentarius (FF25). Whole-cell transformation of AHBS (3-amino-4-hydroxybenzenesulfonic acid) into a phenoxazinone dye was carried out in four different systems: in aqueous media comprising low amounts of carbon and nitrogen source, in buffer, and in distilled water.

Conclusions: This study demonstrated the ability of four fungal strains belonging to the ecological type of white rot fungi to transform precursors into dyes. This paper highlights the potential of fungal biomass for replacing isolated enzymes as a cheaper industrial-grade biocatalyst for the synthesis of dyes and other commercially important products. The use of immobilized fungal biomass limits free migration of cells and facilitates their reuse in a continuous system for precursor transformation.
\end{abstract}

\section{Background}

Investigations of environmentally friendly oxidations represent an important contribution to the development of sustainable processes. In this context, enzyme-catalysed oxidation reactions with air as co-substrate are of considerable current interest. These reactions are low-cost processes, which permit the use of non-toxic reagents in aqueous solvent systems. A majority of oxidative biotransformation processes involve metabolizing cells or isolated enzymes [1]. Fungal laccase, the main oxidase produced by many wood-rotting strains, catalyzes oxida-

* Correspondence: jpolak@poczta.umcs.lublin.pl

1 Department of Biochemistry, Maria Curie-Skłodowska University, Akademicka 19, Lublin, Poland

Full list of author information is available at the end of the article tion of a broad range of organic and non-organic substrates [2,3]. Laccase has the ability to mediate oxidative coupling reactions between aromatic compounds, producing new structures, including coloured products $[4,5]$. Therefore, the use of laccase as a biocatalyst may be an alternative to chemical synthesis of existing or new dyes. Laccase-mediated conversion of phenolic derivatives possessing amino substituents in the ortho position has been reported to yield dyes with the structure of phenoxazinone [6-9] and laccase-mediated conversion of Acid Blue 62 produced a novel azoanthraquinone dye [10].

The production and purification of laccase for industrial purposes is still too expensive to provide for a commercially interesting alternative to chemical synthesis. A cheaper way to utilize the enzymes for the synthesis of 
new compounds could be to use fungal cultures with a well-known ability to produce extracellular laccase. The use of whole cells offers the important advantage of simple, and hence low-cost, catalyst preparation. The use of biomass to synthesize dyes "in situ" could be an efficient way of producing colorants in mild conditions, especially, in terms of chemicals, $\mathrm{pH}$, and temperature. The aim of this study was to examine the ability of four fungal strains to transform simple organic precursors into new colour compounds, which could be used as dyes. Transformation of 17 precursors, known as intermediates applied in the coloration of keratinous fibre [11,12] and cotton and wool knitted fabrics $[13,14]$, was tested using fungal biomass immobilized on selected carriers. Transformation of one of them, 3-amino-4-hydroxybenzenesulfonic acid (AHBS), by a laccase purified from Cerrena unicolor, resulted in the biosynthesis of a novel phenoxazinone dye $[7,9]$. The use of fungal cultures to transform various chemical compounds has already been reported in several studies [15-17] and fungal biomass immobilized on Scotch-Brite $^{\mathrm{rm}}[18]$, alginate beads [19], and stainless steel sponge [20] was utilized for decolouration of textile dyes. This is the first paper on the use of immobilized white rot fungal strains for synthesis of dyes.

\section{Results and Discussion}

To find a new catalyst for synthesis of dyes, the mycelium of white rot fungi with a well-known ability to secrete laccase was used for biotransformation of specific precursors to dyes. The precursors were selected from a list of commercially available chemicals, and the main criteria of selection were their chemical structure (benzene and naphthalene derivatives) and their price [21,22].

\section{Agar-plate screening test}

Agar-plate screening of several different precursors, benzoic and naphthalene derivatives was performed using fungal biomass as a biocatalyst (Table 1). Among these precursors were chemicals consisting of amino-, hydroxy-, nitro-, sulfonic- and carboxy- substituents. The ability of the fungi to grow in the presence of the precursors and to transform the latter into coloured products was monitored during 14 days of the experiment. Colour products were formed during the first days of transformation in the case of the best precursors. In order to check the autoxidation ability of the precursors, the appearance of their coloured products without the presence of actively growing mycelium was monitored (control samples). In the case of six precursors, autoxidation processes of different intensity were observed (Table 2). Two of those precursors, AHNBS and 4AHNS, were rejected from further study because of a very rapid and very intensive autoxidation. In the case of the other four precursors (2,5DABS, DHN, 6AHNS, and 2A3HP), a very slight autoxidation was observed, and these precursors were further tested for their biotransformation by immobilized fungal mycelium.

On the basis of the results obtained from the screening test it was observed that the tested fungal strains had the ability to grow in the presence of $1 \mathrm{mM}$ precursors and to transform them into products of different colour, from yellow and red to green and blue (Table 2). Only in the presence of 2-phenylphenol sodium salt tetrahydrate (2PP), were the mycelia of four fungal strains unable to grow; however a new, red coloured product was formed on an old agar plug, which was used for plate inoculation, probably as the result of the presence of oxidizing enzymes in this fragment of the mycelium. 2PP was recognized as toxic for the tested fungal strains and as such was excluded from further experiments. Five precursors, A2SA, 3ABS, 5SSA, 2FBSA, and HNSA, were not transformed into coloured products by the actively growing mycelium of any of the tested strains and so were also eliminated from future tests (Table 2).

The colour intensity of the products obtained during the biotransformation of the precursors by fungi was analyzed after 7 days of cultivation. This intensity was expressed by different numbers; the value 0 expressed a lack of colour and the values in the range from 1 to 4 expressed a rising intensity of colour. Among the four tested strains, only $A B 123$ and FF25 showed a very high potential for biotransformation of the different precursors (value 4). Three of the tested precursors, AHBS, 2,5DABS, and DHN were transformed by all the strains equally. Additionally in the case of ANS, 2,4DABS, dHBdSA and 6AHNS the most intensive colours of products were obtained after their biotransformation using strain $A B 123$, whereas Cat and 2A3HP were transformed very efficiently by FF25. Strain CU139 showed a medium level of biotransformation efficiency (value 3) in the case of 2,4DABS, Cat and 6AHNS used as precursors. Strain $T V 7$ showed a low level of biotransformation (values from 0 to 2) in the case of 2,4DABS, dHBdSA, Cat and 2A3HP tested as precursors for coloured product formation.

\section{Correlation between electrochemical behaviour of precursors and their transformation to coloured products}

To find correlations between the degree of precursor transformation by fungi and its oxidation potential, cyclic voltammetry $(\mathrm{CV})$ was done. All the tested compounds were characterized using $\mathrm{CV}$ at a graphite working electrode at $\mathrm{pH}$ 4.5. In most cases, they exhibited a welldefined oxidation peak (Eo) and also, for some compounds, a reduction peak $(E r)$. Table 1 presents all obtained Eo and $E r$ values. The precursors displayed oxidation peaks in the potential range from $251 \mathrm{mV}$ (for 4AHNS) to $1013 \mathrm{mV}$ (for A2SA) and reduction peaks in 
Table 1: Characterization of precursors tested using the agar-plate screening test

\begin{tabular}{|c|c|c|c|c|}
\hline Name of precursor & Acronym & Substituents & Eo $(\mathrm{mV})$ & $\operatorname{Er}(\mathrm{mV})$ \\
\hline \multicolumn{5}{|l|}{ benzene derivatives } \\
\hline 1,2-dihydroxybenzene & Cat & $1-\mathrm{OH}, 2-\mathrm{OH}$ & 548 & 285 \\
\hline aniline-2-sulfonic acid & A2SA & $1-\mathrm{SO}_{3} \mathrm{H}, 2-\mathrm{NH}_{2}$ & 1013 & -0.5 \\
\hline 3-aminobenzenesulfonic acid & $3 A B S$ & $1-\mathrm{SO}_{3} \mathrm{H}, 3-\mathrm{NH}_{2}$ & 968 & $5.4^{\mathrm{a}}$ \\
\hline 3-amino-4-hydroxybenzenesulfonic acid & AHBS & $1-\mathrm{SO}_{3} \mathrm{H}, 3-\mathrm{NH}_{2}, 4-\mathrm{OH}$ & 518 & -103 \\
\hline 2,4-diaminobenzenesulfonic acid & $2,4 \mathrm{DABS}$ & $1-\mathrm{SO}_{3} \mathrm{H}, 2-\mathrm{NH}_{2}, 4-\mathrm{NH}_{2}$ & 818 & \\
\hline 2,5-diaminobenzenesulfonic acid & $2,5 \mathrm{DABS}$ & 1- $-\mathrm{SO}_{3} \mathrm{H}, 2-\mathrm{NH}_{2}, 5-\mathrm{NH}_{2}$ & 433 & $-356^{a}$ \\
\hline 3-amino-4-hydroxy-5-nitrobenzenesulfonic acid & AHNBS & $1-\mathrm{SO}_{3} \mathrm{H}, 3-\mathrm{NH}_{2}, 4-\mathrm{OH}, 5-\mathrm{NO}_{2}$ & $339 a, 579$ & -92 \\
\hline 5-sulfosalicylic acid hydrate & $5 S S A$ & 1- $\mathrm{COOH}, 2-\mathrm{OH}, 5-\mathrm{SO}_{3} \mathrm{H}$ & - & - \\
\hline 2-formylbenzenesulfonic acid sodium salt & 2FBSA & $1-\mathrm{SO}_{3} \mathrm{Na}, 2-\mathrm{CHO}$ & - & - \\
\hline 4,5-dihydroxy-1,3-benzene-disulfonic acid & dHBdSA & $1-\mathrm{SO}_{3} \mathrm{Na}, 3-\mathrm{SO}_{3} \mathrm{Na}, 4-\mathrm{OH}, 5-\mathrm{OH}$ & $914^{b}$ & \\
\hline 2-amino-3-hydroxypyridine & $2 \mathrm{~A} 3 \mathrm{HP}$ & $2-\mathrm{NH}_{2}, 3-\mathrm{OH}$ & 647 & $144,6.8$ \\
\hline 2-phenylphenol sodium salt tetrahydrate & $2 \mathrm{PP}$ & $2-\mathrm{ONa}$ & 790 & \\
\hline \multicolumn{5}{|l|}{ naphtalene derivatives } \\
\hline 2,7-dihydroxynaphtalene & $\mathrm{DHN}$ & $2-\mathrm{OH}, 7-\mathrm{OH}$ & 672 & \\
\hline 6-hydroxy-2-naphthalenesulfonic acid sodium salt & HNSA & $2-\mathrm{SO}_{3} \mathrm{Na}, 6-\mathrm{OH}$ & 893 & -144 \\
\hline 4-amino-3-hydroxy-1-naphthalenesulfonic acid & 4AHNS & $1-\mathrm{SO}_{3} \mathrm{Na}, 3-\mathrm{OH}, 4-\mathrm{NH}_{2}$ & 251 & $194,-1.4$ \\
\hline 6-amino-4-hydroxy-2-naphthalenesulfonic acid & 6AHNS & 2-SO $\mathrm{Sa}, 4-\mathrm{OH}, 6-\mathrm{NH}_{2}$ & 499 & \\
\hline 5-amino-1-naphthalenesulfonic acid & ANS & $1-\mathrm{SO}_{3} \mathrm{Na}, 5-\mathrm{NH}_{2}$ & 680 & \\
\hline
\end{tabular}

Table summarizes the chemical structure of precursors in comparison with their oxidation ( $E$ o) and reduction (Er) potentials. The potentials of the precursors were obtained at the scan rate $50 \mathrm{mV} / \mathrm{s}$ with the exception of dHBdSA, which was tested at the scan rate $25 \mathrm{mV} / \mathrm{s}$. ${ }^{\text {a }}$ very small peak, ${ }^{b}$ scan rate $-25 \mathrm{mV} / \mathrm{s}$.

the range from $-356 \mathrm{mV}$ (for 2,5DABS) to $285 \mathrm{mV}$ (for Cat) at a scan rate of $50 \mathrm{mV} / \mathrm{s}$. Only precursor dHBdSA displayed an oxidation potential at a scan rate of $25 \mathrm{mV} / \mathrm{s}$. Out of all the tested precursors, only two compounds (5SSA and 2FBSA) did not exhibit both the oxidation and the reduction peaks at scan rates of 25 to $200 \mathrm{mV} / \mathrm{s}$. For the nine substances, the oxidation reaction was reversible, and during $\mathrm{CV}$ both the oxidation and the reduction peaks were measurable (Table 1 ).

All the tested precursors (Table 1) possessed at least one of the following groups as substituents: $-\mathrm{NH}_{2}$,$\mathrm{COOH},-\mathrm{CHO}$ and $-\mathrm{OH}$, and there were just these groups that could be oxidized by laccase $[23,24]$. The precursors which were transformed by fungal laccase and simultaneously did not exhibit a high autoxidation level displayed the potentials which were comparable with the values of redox potentials of fungal LACs in the range from 500 to $800 \mathrm{mV}$ [23]. Among these precursors were compounds belonging to dihydroxy- (Cat, DHN), amino- (ANS), or diamino- (2,4DABS, 2,5DABS) substituted compounds or precursors containing both amino and hydroxy groups (AHBS, 2A3HP, 6AHNS). All those precursors were transformed by the tested strains into coloured products during agar-plate screening tests. The value of $E o$ for the mentioned precursors ranged from $433 \mathrm{mV}$ (2,5DABS) to $680 \mathrm{mV}$ (ANS), and these precursors were transformed into intensively coloured products. The precursors with very high autoxidation ability (4AHNS and AHNBS) demonstrated oxidation peaks at $251 \mathrm{mV}$ and $339 \mathrm{mV}$, respectively. Substrates with the value of Eo near 1000 $\mathrm{mV}$ (A2SA, 3ABS, and HNSA) and substrates which did not exhibit any value of redox potential (2FBSA and 5SSA) were not oxidized by the tested fungal strains. In the case of nine precursors, the presence of a reduction peak was noted (Table 1). Figure 1 presents a cyclic voltammogram of AHBS as an example of quasi-reversible behaviour with an oxidation potential of $518 \mathrm{mV}$ and a small reduction potential of $-103 \mathrm{mV}$.

\section{Transformation in liquid cultures}

As a next step of this work, liquid cultures were tested to select (1) the best fungal strains for transformation, (2) the best carrier for fungal biomass immobilization, and (3) the best precursor for its possible transformation into 
Table 2: Colour and its intensity for products obtained after transformation of precursors during agar-plate screening tests

\begin{tabular}{|c|c|c|c|c|c|c|}
\hline \multirow[t]{2}{*}{ Precursor } & \multirow[t]{2}{*}{ Precursors autoxidation* } & \multirow[t]{2}{*}{ Colour of product } & \multicolumn{4}{|c|}{ Intensity of products colour** } \\
\hline & & & TV7 & FF25 & $A B 123$ & CU139 \\
\hline \multicolumn{7}{|c|}{ precursors transformed by fungi } \\
\hline AHBS & - & orange & 4 & 4 & 4 & 4 \\
\hline ANS & - & orange/red & 3 & 2 & 4 & 2 \\
\hline $2,4 \mathrm{DABS}$ & - & brown & 1 & 2 & 4 & 3 \\
\hline dHBdSA & - & yellow/orange & 1 & 3 & 4 & 2 \\
\hline Cat & - & brown & 0 & 4 & 2 & 3 \\
\hline \multicolumn{7}{|c|}{ precursors about low ability to autoxidation } \\
\hline $2,5 \mathrm{DABS}$ & $-/+$ & purple red & 4 & 4 & 4 & 4 \\
\hline $\mathrm{DHN}$ & $-/+$ & green/blue & 4 & 4 & 4 & 4 \\
\hline 6AHNS & $-/+$ & purple/red & 4 & 3 & 4 & 3 \\
\hline $2 \mathrm{~A} 3 \mathrm{HP}$ & $-/+$ & yellow/orange & 1 & 4 & 3 & 2 \\
\hline \multicolumn{7}{|c|}{ precursors about high ability to autoxidation } \\
\hline AHNBS & + & orange & AO & AO & AO & AO \\
\hline 4AHNS & ++ & red & AO & AO & AO & AO \\
\hline \multicolumn{7}{|c|}{ precursors non-transformed by fungi } \\
\hline $\mathrm{A} 2 \mathrm{SA}$ & - & none & 0 & 0 & 0 & 0 \\
\hline $3 A B S$ & - & none & 0 & 0 & 0 & 0 \\
\hline $5 S S A$ & - & none & 0 & 0 & 0 & 0 \\
\hline $2 \mathrm{FBSA}$ & - & none & 0 & 0 & 0 & 0 \\
\hline HNSA & - & none & 0 & 0 & 0 & 0 \\
\hline 2PP & - & none & 0 & 0 & 0 & 0 \\
\hline
\end{tabular}

coloured products. Only five precursors selected during agar-plate screening were tested using liquid cultures, and these included 2,5DABS, AHBS, 2A3HP, ANS, and DHN.

\section{Immobilization of fungal biomass}

To find the best support for immobilization of fungi, cheap and easy to handle supports, such as plastic mesh scourer (PMS), cellulose cook filter (CCF), and polyurethane sponge (PUS) were tested, to check the ability of white rot fungi to overgrow the support and to secrete LAC. Four fungal strains with a well-known ability to produce extracellular laccase [25-28] were used in the immobilization experiment. All the tested strains were able to adhere to the supports just after 1 day of cultivation and tightly overgrow their structure during the next 5-7 days. Only in the case of PUS, was the mycelium of all the tested strains unable to overgrow the support tightly and consequently many free pieces of mycelium were observed in the medium during the cultivation period. Figure 2 presents the activity of extracellular LAC (U/g) recorded on the $7^{\text {th }}$ day of cultivation for mycelium immobilized on PMS, CCF, or PUS as a support. It was observed that the activity of extracellular LAC secreted by mycelia of $T V 7, F F 25$, and $A B 123$ immobilized on PUS was higher in comparison to the activity of LAC secreted by strains immobilized on PMS and CCF (Figure 2). The activity of LAC secreted by non-immobilized mycelia of the four tested strains was on average 50 times higher (data not shown) in comparison to the mycelia immobilized on the PMS and CCF supports. The obtained data confirmed the low ability of immobilized mycelium to secrete LAC [28]. However, the use of immobilized biomass limited free migration of cells and facilitated its reuse in a continuous system for precursor transforma- 


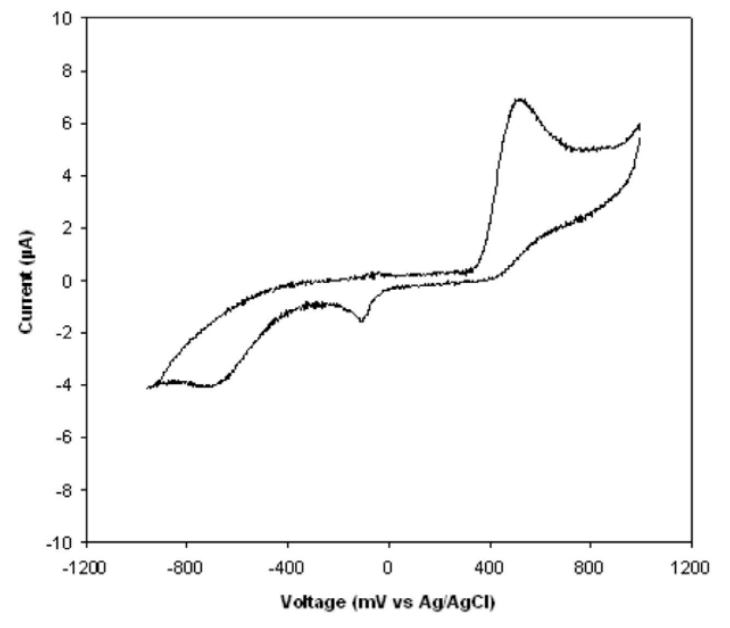

Figure 1 Cyclic voltammograms of AHBS at graphite working electrode ( $\mathbf{A g} / \mathbf{A g C l}$ reference). Solution containing $1 \mathrm{mM} \mathrm{AHBS}$ and $100 \mathrm{mM} \mathrm{Na}$-tartrate buffer ( $\mathrm{pH} 4.5$ ) was scanned at a scan rate of 50 $\mathrm{mV} / \mathrm{s}$, first scan.

tion. The level of laccase monitored in the immobilized fungal cultures was sufficient to apply this system for transformation of precursors into coloured products. Taking into account the results of this step of the experiment, the strains immobilized on plastic mesh scourer (PMS) were used for precursor biotransformation in liquid cultures.

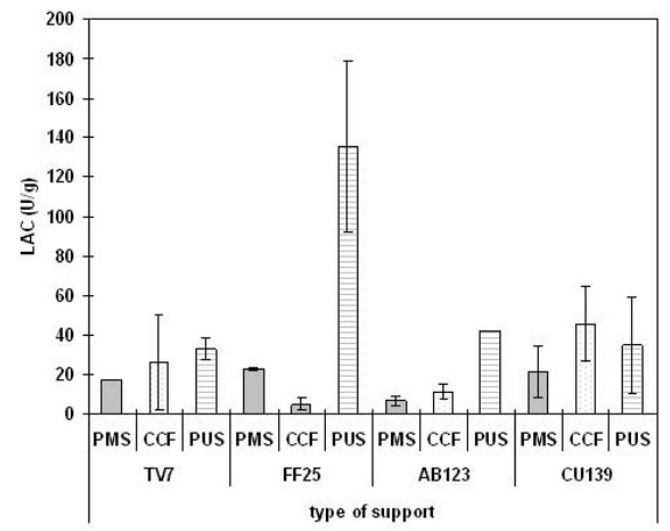

Figure $\mathbf{2}$ Influence of the type of fungal biomass immobilization on laccase secretion by the tested strains. Fungal biomass of four fungal strains, Trametes versicolor (TV7), Fomes fomentarius (FF25), Abortiporus biennis (AB123), and Cerrena unicolor (CU139), was immobilized on plastic mesh scourer (PMS), cellulose cook filter (CCF) and polyurethane sponge (PUS). The activity of extracellular laccase (LAC) was recorded on the $7^{\text {th }}$ day of cultivation of the four fungal strains.

\section{Transformation of precursors and preliminary}

\section{characterization of products}

To find out which fungal strain was the best biocatalyst for dye synthesis, biotransformation of precursors 2,5DABS, AHBS, 2A3HP, ANS, and DHN was carried out using liquid cultures of immobilized biomass of the four fungal strains. These precursors were selected during the agar plate screening test. The transformation of the precursors was monitored using UV-vis absorption spectroscopy, and the maximum absorbances of the obtained products were determined based on a UV-vis spectrum in the range from 200 to $700 \mathrm{~nm}$. The amount of product obtained during 48 hours of transformation was expressed as absorbance at a maximum monitored in UV-vis spectroscopy (Table 3).

After transformation of 2A3HP and AHBS by fungal biomass, yellow-orange coloured products were obtained. UV-vis spectra of those products showed a double peak at the wavelengths of 420 to $440 \mathrm{~nm}$ (Figure 3A, 3B). Fungal-mediated conversion of AHBS yielded a product with a typical UV-vis spectrum characteristic of phenoxazinone-type compounds, and laccase was shown to be responsible for this biotransformation [6-9,29-32].

In the case of 2,5DABS, it was observed that in the presence of fungal biomass, a slightly coloured medium containing the precursor turned into a red product after a very short time of cultivation. The UV-vis spectrum of the obtained product strongly depended on the $\mathrm{pH}$, and the absorbance for this product was determined for two different wavelengths (460 $\mathrm{nm}$ and $544 \mathrm{~nm}$ ), afterwards presented as the sum of absorbances at these two wavelengths (Figure 3C). A similar product, described as poly(2,5-diaminobenzenesulfonate), was obtained after transformation of 2,5DABS by horseradish peroxidase but with the necessity of adding hydrogen peroxide [33].

Three precursors, 2,5DABS, AHBS, and 2A3HP, were transformed into products with very intensive colours, whereas the intensity of the products obtained after DHN and ANS transformation was very low. In the case of the DHN precursor, the green-blue product of its transformation displayed a maximum at $590 \mathrm{~nm}$ (Figure 3D). The red product of ANS transformation had a maximum at 460 and $490 \mathrm{~nm}$ (Figure 3E), in contrast to a product obtained using chemical transformation of ANS described by Patel and Dasoni [34] with a maximum at $370 \mathrm{~nm}$.

The maximum absorbance of products was determined during 48 hours of transformation (Table 3). Out of the five tested precursors, four yielded maximum amounts of products after transformation by FF25, with the exception of the precursor ANS, which was transformed at nearly the same ratio by three other strains (TV7, FF25, and $A B 123)$. In the liquid cultures, the lowest absorbances of products were obtained after transformation of 
Table 3: Maximum absorbance of products obtained during 48 hours of whole-cell biotransformation of selected precursors

\begin{tabular}{|c|c|c|c|c|c|}
\hline \multirow[t]{2}{*}{ Precursor } & \multirow{2}{*}{ Wavelength of product $\lambda_{\max }(\mathrm{nm})$} & \multicolumn{4}{|c|}{ Absorbance of product (Abs) } \\
\hline & & $T V 7$ & FF25 & $A B 123$ & CU139 \\
\hline 2,5DABS & 460,544 & $5.40 \pm 0.05$ & $6.89 \pm 0.03$ & $5.18 \pm 0.02$ & $3.24 \pm 0.43$ \\
\hline AHBS & 436 & $5.94 \pm 0.11$ & $8.62 \pm 0.26$ & $5.84 \pm 0.06$ & $3.37 \pm 3.49$ \\
\hline 2A3HP & 420 & $4.79 \pm 0.18$ & $7.85 \pm 0.00$ & $6.39 \pm 0.07$ & $3.61 \pm 1.69$ \\
\hline ANS & 490 & $0.71 \pm 0.02$ & $0.70 \pm 0.00$ & $0.71 \pm 0.04$ & $0.39 \pm 0.14$ \\
\hline DHN & 590 & $0.18 \pm 0.03$ & $1.00 \pm 0.00$ & $0.87 \pm 0.10$ & $0.66 \pm 0.39$ \\
\hline
\end{tabular}

Biotransformation of selected precursors was carried out in liquid cultures of four fungal strains (TV7, FF25, AB123, and CU139) immobilized on PMS. Absorbance of products was monitored spectrophotometrically after 48 hours.

all the tested precursors by strain CU139, contrary to the agar-plate screening test, in which $T V 7$ demonstrated the lowest transformation level for most of the tested precursors.

\section{Influence of $\mathrm{pH}$}

An extremely important factor determining the yield of enzymatic biotransformation of aromatic precursors is the value of the reaction mixture $\mathrm{pH}$, which influences the catalytic activity of enzymes, precursor redox potential, and ionization of precursor substituents [35,36]. Usually the first step in enzyme-assisted catalysis is to optimize its parameters, among them the value of the $\mathrm{pH}$. Generally, in enzyme biocatalysis, the $\mathrm{pH}$ is adjusted to a suitable value prior to the initiation of the reaction and in some cases it is controlled over time.

In this work, different reaction mixtures consisting precursors suspended in GPA medium with a specific $\mathrm{pH}$ were tested in liquid cultures. During the transformation of the selected precursors by fungal biomass it was observed that the tested strains adjusted the $\mathrm{pH}$ of the reaction mixture to the specific values characteristic of each strain (Table 4). Visible differences between the initial value of $\mathrm{pH}$ and the value of $\mathrm{pH}$ after 7 days of cultivation were observed for all the fungal strains. Only in CU139 cultures the $\mathrm{pH}$ values of the transformation mixture increased to basic ( $\mathrm{pH} 8.3$ ), whereas in $T V 7$ cultures the $\mathrm{pH}$ values decreased to more acidic $(\mathrm{pH} 4.8)$ ones both in the solutions with the addition of precursors and in controls without their addition. The two remaining strains, $F F 25$ and $A B 123$, had the ability to adjust the $\mathrm{pH}$ values of the transformation mixtures to levels within a range from 5 to 6 .

Fungi grow over a wide $\mathrm{pH}$ range, with the optimum $\mathrm{pH}$ in the weak acid range, which is connected with the natural role of oxidizing enzymes secreted by fungi involved in biodegradation of lignin [37]. Our study demonstrates the ability of fungi to modify the $\mathrm{pH}$ values of culture medium already after 24 hours of cultivation. Consistently with our results, Moreira Neto and co-workers described the ability of Lentinus crinitus and Psilocybe castanella to modify the $\mathrm{pH}$ value of the culture medium, which was found to be an important parameter for both the growth of the mentioned fungal strains and the enzymatic system involved in RBBR decolourization [38].

\section{Optimization of AHBS transformation by fungal biomass}

Based on all the performed experiments and the obtained data, the precursor AHBS was selected for the next step of the study. AHBS was transformed by FF25 immobilized on plastic mesh scourer, which had been selected as the best biocatalyst and the best carrier, respectively.

To find the yield of transformation of the precursor by FF25, three different concentrations of AHBS (1, 5, 10 $\mathrm{mM}$ ) were incubated in four different transformation systems: system A - $1 \mathrm{mM} \mathrm{Na-tartrate} \mathrm{buffer,} \mathrm{system} \mathrm{B} \mathrm{-} \mathrm{dis-}$ tilled water, system $\mathrm{C}$ - 100 times diluted GPA medium, system D - 10 times diluted GPA medium. The consumption of the precursor over time was monitored using capillary electrophoresis. In the case of low precursor concentrations ( $1 \mathrm{mM}$ and $5 \mathrm{mM}$ ), the type of system applied had no influence on the yield of AHBS transformation, and this precursor was transformed completely after 24 hours (Figure 4). The presence of $0.8 \mathrm{mM}$ of AHBS in the reaction mixture after 24 hours of transformation was only observed for $5 \mathrm{mM}$ AHBS incubated in Na-tartrate buffer.

The higher concentration of AHBS $(10 \mathrm{mM})$ was not transformed as effectively as the lower one $(5 \mathrm{mM})$ during 24 hours, regardless of the transformation system applied. More than $50 \%$ of AHBS concentration was transformed during 24 hours only in the case of both the 100 and 10 times diluted GPA medium (system C and D). These systems were the most effective for transformation of this concentration of precursor what was correlated 

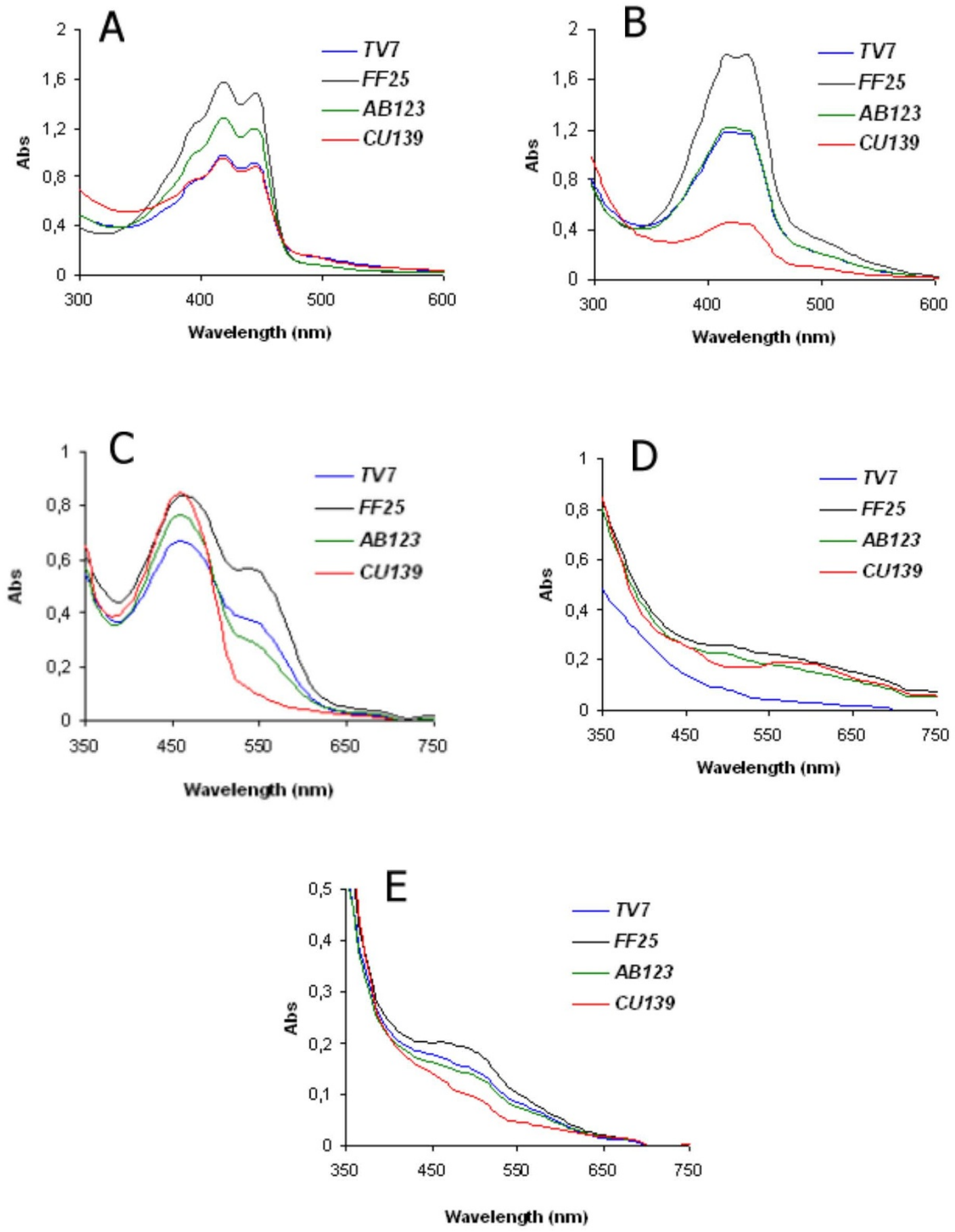

Figure 3 UV-vis spectra of products obtained after transformation of selected precursors. Whole-cell biotransformation of precursors $2 \mathrm{~A} 3 \mathrm{HP}$ (A), AHBS (B), 2,5DABS (C), DHN (D), and ANS (E) was performed in liquid cultures of four fungal strains (TV7, FF25, AB123, and CU139) immobilized on PMS. 
Table 4: The ability of the tested strains to modify the pH of the transformation medium during cultivation

\begin{tabular}{|c|c|c|c|c|c|c|}
\hline Strain & 2A3HP & 2,5DABS & ANS & AHBS & DHN & $\begin{array}{l}\text { Control I } \\
\text { (without precursor) }\end{array}$ \\
\hline & \multicolumn{6}{|c|}{ initialpH } \\
\hline & 8.6 & 6.9 & 6.7 & 5.2 & 8.6 & 6.7 \\
\hline & \multicolumn{6}{|c|}{ after 24 hours } \\
\hline$T V 7$ & 5.3 & 5.0 & 4.8 & 4.9 & 6 & 4.8 \\
\hline$F F 25$ & 5.8 & 6.3 & 5.5 & 5.1 & nd & 5.0 \\
\hline$A B 123$ & 5.0 & 5.2 & 5.2 & 4.9 & 5.6 & 5.0 \\
\hline CU139 & 6.5 & 6.7 & 6.2 & 8.0 & 7.0 & 6.7 \\
\hline \multirow[t]{2}{*}{$\begin{array}{l}\text { Control II } \\
\text { (without strain) }\end{array}$} & 7.9 & 6.8 & 6.5 & 5.2 & 7.9 & 6.7 \\
\hline & \multicolumn{6}{|c|}{ after 7 days } \\
\hline TV7 & 6.5 & 4.6 & 4.6 & 4.8 & 6.0 & 4.8 \\
\hline FF25 & 6.0 & 6.4 & 6.2 & 5.4 & nd & 5.4 \\
\hline$A B 123$ & 5.7 & 5.6 & 5.9 & 5.6 & 5.6 & 4.9 \\
\hline CU139 & 8.3 & 8.3 & 8.3 & 8.1 & 7.0 & 8.3 \\
\hline $\begin{array}{l}\text { Control II } \\
\text { (without strain) }\end{array}$ & 7.5 & 7.0 & 6.8 & 5.2 & 7.9 & 6.7 \\
\hline
\end{tabular}

with the highest absorbance of obtained product (Figure 5).

FF25 had the ability to transform $1 \mathrm{mM}$ and $5 \mathrm{mM}$ AHBS even when the strain was incubated in water or in buffer. However, the lack of nutrition over the long time of cultivation resulted in reduced biomass activity and transformation efficiency of the higher concentration of the precursor. The application of diluted GPA medium was preferable to water or to buffer. It was shown that the proposed system may be applied for the transformation of AHBS into a phenoxazinone dye, which had previously been described for the transformation of this precursor by a fungal laccase $[7,9]$.

The use of fungal biomass for the transformation of precursors does not require adjustment of the $\mathrm{pH}$ by adding appropriate ions, thus offering several advantages. The application of laccase-secreting fungal biomass as a whole-cell biocatalyst can result, as is the case with natural degradation of lignin, in synchronized action of the intra- and extracellular oxidizing enzymes and lowmolecular-weight fungal metabolites which could play a significant role as mediators in oxidation of a wide range of chemicals [39].

\section{Toxicity analysis of products}

The cytotoxicity of precursors and products was tested using the Neutral Red uptake assay (NRU) with Caco-2 cells (Table 5). The EU classifies a chemical to be not environmentally toxic if the $\mathrm{IC}_{50}$ is above $0.1 \mathrm{mg} / \mathrm{mL}$, which was the case for the selected products as measured with the NRU test. Among the five tested precursors, $2 \mathrm{~A} 3 \mathrm{HP}$ and DHN showed a significant toxicity, $\mathrm{IC}_{50}=$ $0.055 \mathrm{mg} / \mathrm{mL}$ and $\mathrm{IC}_{50}=0.107 \mathrm{mg} / \mathrm{mL}$, respectively, in contrast to dyes obtained from their transformation, which had $\mathrm{IC}_{50}$ 's higher than $1 \mathrm{mg} / \mathrm{mL}$, which is equivalent to very low toxicity. The dye obtained after transformation of 2,5DABS using FF25 had an $\mathrm{IC}_{50}$ of $0.57 \mathrm{mg} /$ $\mathrm{mL}$, whereas two other samples of this dye, obtained after 2,5DABS transformation by $A B 123$ and CU139, were non toxic $\left(\mathrm{IC}_{50}>1 \mathrm{mg} / \mathrm{mL}\right)$. In the case of the dyes obtained after transformation of AHBS and ANS by FF25, AB123, 


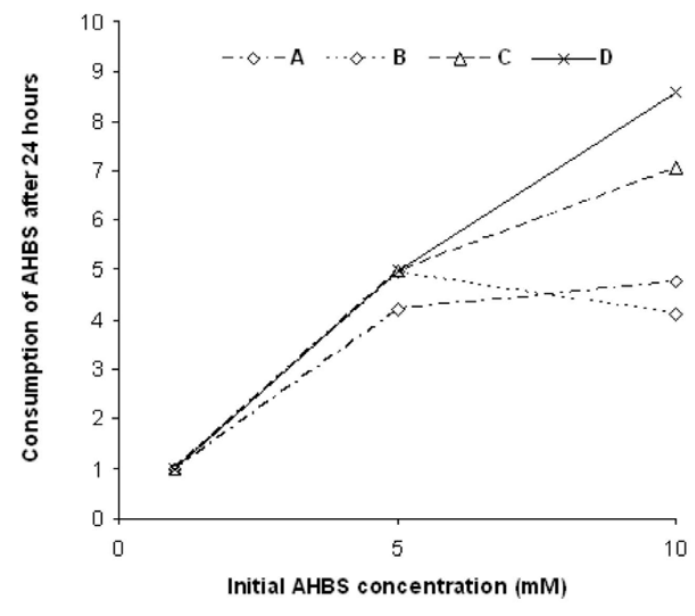

Figure $\mathbf{4}$ Consumption of AHBS by strain FF25. Consumption of AHBS by Fomes fomentarius (FF25) was observed after 24 hours of incubation of three different AHBS concentrations (1,5 and $10 \mathrm{mM})$ dissolved in four different transformation media: A - $1 \mathrm{mM}$ Na-tartrate buffer, B - distilled water, C - 100 times diluted GPA medium, D - 10 times diluted GPA medium.

or $T V 7$, all the samples had $\mathrm{IC}_{50}$ 's of more than $1 \mathrm{mg} / \mathrm{mL}$ and were essentially non-toxic. In the case of control cultures, growing without the addition of precursors, only the sample of $T V 7$ was slightly toxic $\left(\mathrm{IC}_{50}=0.85 \mathrm{mg} / \mathrm{mL}\right)$

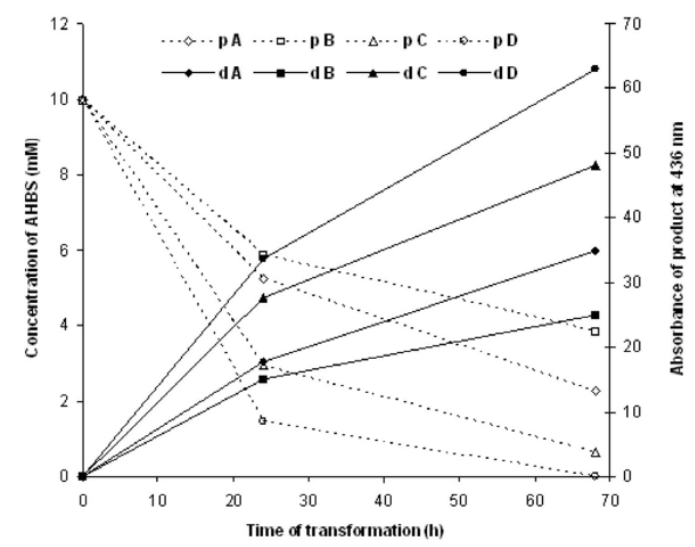

Figure 5 Consumption of AHBS (p) and formation of the phenoxazinone dye (d) during 68 hours of transformation by strain FF25. Consumption of precursor was monitored using MEKC, whereas formation of product was monitored spectrophotometrically at $436 \mathrm{~nm}$. Transformation of $10 \mathrm{mM}$ AHBS was carried out in four different transformation media: A - 1 mM Na-tartrate buffer, B - distilled water, C - 100 times diluted GPA medium, $D-10$ times diluted GPA medium. pA (pB, $p C, p D)$ - concentration of precursor (AHBS) in system $A(B, C, D) . d A$ $(d B, d C, d D)$ - absorbance of product (phenoxazinone dye) in system $A$ $(B, C, D)$ while other control cultures (AB123, CU139, and FF25) had $\mathrm{IC}_{50}$ 's higher than one (Table 5).

\section{Conclusions}

This work is a preliminary attempt to estimate the capability of white rot fungi to be used in dye synthesis (Figure 6). Seventeen different precursors were tested as substrates for transformation by actively growing fungal biomass. Transformation of the selected precursors into intensive and non-toxic products was studied in liquid culture. The use of the fungi resulted in stable products lasting for a long time without specific stabilization. Further advantages included the simplicity of the process and the use of oxygen as a "clean oxidant". Further applicability of the fungi in the synthesis of new, coloured molecules is currently being investigated by our group. All the promising coloured products obtained in those investigations will be tested for their application as textile dyes as some preliminary results have already demonstrated that these products have valuable dyeing properties.

\section{Methods}

\section{Chemicals}

All the precursors were purchased from Sigma-AldrichFluka Company and were used without further purification (Table 1). Stock solutions of the precursors were prepared in MiliQ water with or without the addition of sodium hydroxide for better solubilisation. The stock solutions of AHNBS, 5SSA, 2FBSA, and dHBdSA were prepared without the addition of $\mathrm{NaOH}$ (Millipore, USA), but in the case of A2SA, 3ABS, AHBS, 2,4DABS, 2,5DABS, 2A3HP, 2PP, HNSA, DHN, 4AHNS, 6AHNS, and ANS, the addition of $\mathrm{NaOH}$ was necessary for better solubilisation. The concentration of $\mathrm{NaOH}$ in precursor stock solutions did not exceed $1 \mathrm{mM}$. Catechol was the only precursor that required solubilisation by $50 \%$ ethanol, but the concentration of the alcohol in the biotransformation mixture did not exceed $1 \%$. All the precursors were filter sterilized (Millipore, USA) and added to an appropriate sterilized medium to a final concentration of $1 \mathrm{mM}$. The structures of compounds with functional substituents are summarized in Table 1.

\section{Electrochemical potential of precursors}

Cyclic voltammetry of the tested precursors was performed using an MTM-Anko apparatus type M161 (Poland) equipped with a graphite working electrode, a platinum counter electrode, and an $\mathrm{Ag} / \mathrm{AgCl}$ reference electrode. The precursors were dissolved using $100 \mathrm{mM}$ Na-tartrate buffer, $\mathrm{pH} 4.5$, to $1 \mathrm{mM}$ final concentration. All the precursors were tested at a scan rate of $50 \mathrm{mV} / \mathrm{s}$; however, the precursors which did not display both the oxidation and the reduction potential at this scan rate were tested the scan rate varied from 25 to $200 \mathrm{mV} / \mathrm{s}$ 
Table 5: Results of NRU assay of cytotoxicity tests done for precursors and products of transformation mediated by fungal strains (TV7, FF25, AB123, and CU139)

\begin{tabular}{|c|c|c|c|}
\hline \multirow[t]{2}{*}{ Precursor } & \multicolumn{2}{|l|}{$I C_{50}(\mathrm{mg} / \mathrm{mL})$} & \multirow[t]{2}{*}{ Strain used for biotransformation } \\
\hline & Precursor & Product & \\
\hline \multirow[t]{2}{*}{ 2,5DABS } & $>1$ & $0.57+/-0.11$ & $F F 25$ \\
\hline & & $>1$ & $C U 139, A B 123$ \\
\hline DHN & $0.107+/-0.0036$ & $>1$ & CU139 \\
\hline AHBS & $>1$ & $>1$ & $F F 25, A B 123$ \\
\hline ANS & $>1$ & $>1$ & $T V 7, A B 123$ \\
\hline 2A3HP & $0.055+/-0.028$ & $>1$ & $A B 123$ \\
\hline
\end{tabular}

(Table 1). All potentials in this work were referred to the $\mathrm{Ag} / \mathrm{AgCl}$ reference electrode.

\section{Organisms and culture conditions}

The fungal strains of Trametes versicolor (L. ex Fr.) Pil (TV7), Fomes fomentarius (L. ex Fr.) Kickx. (FF25), Abortiporus biennis (Bull. ex Fr.) Sing. (AB123), and Cerrena unicolor (Bull. ex Fr.) Murr. (CU139) were obtained from the Fungal Collection of the Biochemistry Department, Maria Curie-Sklodowska University (Lublin, Poland). The inoculation material was precultivated on $2 \%(\mathrm{w} / \mathrm{v})$ malt extract agar (MEA) at $25^{\circ} \mathrm{C}$. The biotransformation experiments, both in the micro-plate screening tests and in liquid cultures, were performed using modified potato

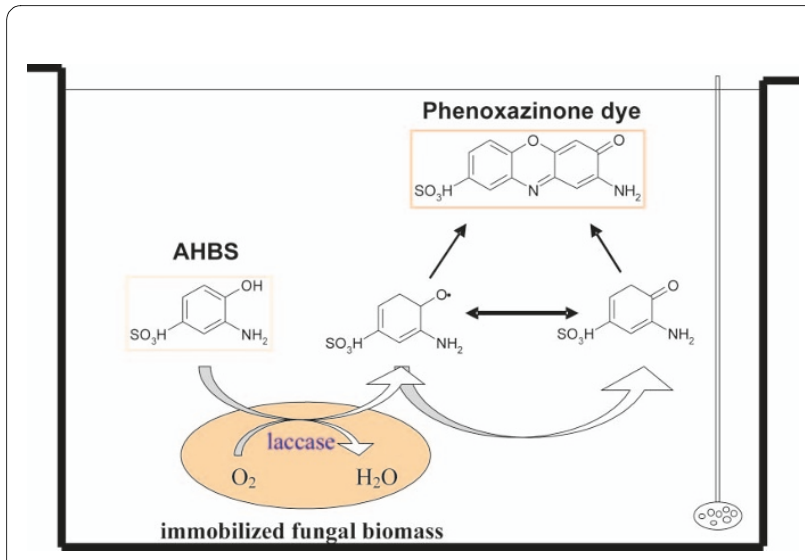

Figure 6 Conversion of 3-amino-4-hydroxybenzenesulfonic acid (AHBS) by immobilized fungal biomass. AHBS is oxidized to the phenoxy radicals and/or quinones, which can coupled non-enzymatically to coloured phenoxazinone compound [7]. medium (GPA). The composition of the GPA medium was as follows: $10 \mathrm{~g} / \mathrm{L}$ glucose, $4 \mathrm{~g} / \mathrm{L}$ potato extract, $1.5 \mathrm{~g} /$ $\mathrm{L}$ asparagine, and $1 \mathrm{~g} / \mathrm{L}$ peptone; in the case of solid cultures, $20 \mathrm{~g} / \mathrm{L}$ of agar was added to the medium.

\section{Immobilization of biomass}

In order to select the best carrier for the immobilization of mycelium, three different inexpensive carriers were tested - plastic mesh scourer (PMS) (Stella, Poland), cellulose cook filter (CCF) (Vileda GMBH, Germany), and polyurethane sponge (PUS) (F.H. Lider, Poland), with an average weight of $1.15 \mathrm{~g}, 0.48 \mathrm{~g}$, and $0.50 \mathrm{~g}$ per $100 \mathrm{~mL}$ of medium, respectively. The carriers were placed in 250mL flasks containing $100 \mathrm{~mL}$ of the GPA medium. After autoclaving, the flasks were inoculated with $3 \mathrm{~mL}$ of 14 day-old mycelium homogenized using a laboratory disperser (IKA-Werke GmbH, Germany) and incubated at $28^{\circ} \mathrm{C} \pm 2$ on a rotary shaker at $140 \mathrm{rpm}$.

\section{Transformation of precursors}

Biotransformation of the precursors by the fungal strains was performed using the solid cultures tested in the agarplate screening test or using liquid cultures in Erlenmeyer flasks.

\section{Solid cultures (agar-plate screening test)}

The agar-plate screening test was performed using sterile 24-well tissue culture plates (16.2 $\mathrm{mm}$ in diameter). Each well contained $2.5 \mathrm{~mL}( \pm 0.2 \mathrm{~mL})$ of sterile GPA medium with the addition of $2 \%$ agar and a precursor at a concentration of $1 \mathrm{mM}$. Each well was inoculated with one agar plug (3 mm in diameter) from the leading edge of colony, which had been maintained on MEA for at least 7 days at $25^{\circ} \mathrm{C}$. The plates were incubated at $25^{\circ} \mathrm{C}$, and the ability of 
the fungi to grow and transform the precursors into coloured products was monitored over the next 14 days.

\section{Liquid cultures (Erlenmeyer flasks)}

Liquid cultures were performed in 50-mL Erlenmeyer flasks containing fungal mycelium immobilized on plastic mesh scourer and $25 \mathrm{~mL}$ of GPA medium. After the carrier was overgrown by the mycelium, the cultivation fluid was decanted and the immobilized mycelium was poured over the biotransformation mixture containing $1 \mathrm{mM}$ of precursor suspended in 10 times diluted GPA medium. Maximal absorbance of the products obtained during 48hour transformation of the selected precursors was recorded at a specific wavelength characteristic of each product.

The $\mathrm{pH}$ of the biotransformation mixtures containing the tested precursors was not adjusted to a specific value in order to ensure sterility of the culture. The $\mathrm{pH}$ values of the transformation mixtures were tested directly after the addition of the precursors (initial $\mathrm{pH}$, time 0 ), after 24 hours, and after 7 days of biotransformation.

\section{Optimisation of AHBS transformation by fungal biomass}

Transformation of AHBS at concentrations of 1,5 , and 10 $\mathrm{mM}$ by strain FF25 immobilized on plastic mesh scourer was performed in 250-mL Erlenmeyer flasks. An appropriate amount of the precursor was dissolved in different transformation media: (A) $1 \mathrm{mM}$ tartrate buffer, (B) distilled water, (C) 100 times diluted GPA medium, and (D) 10 times diluted GPA medium. The transformation was carried out for 48 hours in the case of $1 \mathrm{mM}$ and $5 \mathrm{mM}$ precursor concentrations and for 168 hours in the case of $10 \mathrm{mM}$ AHBS in shaking cultures $\left(140 \mathrm{rpm}, 25^{\circ} \mathrm{C}\right)$. The consumption of AHBS during the transformation was determined using MEKC analysis at 24-hour intervals.

\section{Determination of laccase activity}

The activity of extracellular laccase (LAC) was determined following oxidation of $2.5 \mathrm{mM}$ 2,2'-azino-bis(3ethylbenzthiazoline-6-sulphonic acid) (ABTS) in $100 \mathrm{mM}$ $\mathrm{Na}$-tartrate buffer at $\mathrm{pH} 3$ [40]. The oxidation of ABTS was monitored spectrophotometrically at $414 \mathrm{~nm}\left(\varepsilon_{414}=\right.$ $\left.36048 \mathrm{M}^{-1} \mathrm{~cm}^{-1}\right)$. LAC activity was expressed in $\mathrm{U}$ per litre of culture fluid (U/L) or in $U$ per $1 \mathrm{~g}$ of mycelium dry weight (U/g). One unit of LAC (U) oxidized $1 \mu \mathrm{mol}$ of ABTS per $1 \mathrm{~min}$ at $25^{\circ} \mathrm{C}$.

\section{Evaluation of precursor and product toxicity}

The toxicity of precursors and products was evaluated using the Neutral Red uptake assay (NRU) with Caco-2 human intestinal cell-line as an in vitro test system [10]. Samples of products were lyophilized and then dissolved in dimethyl sulfoxide (DMSO) to a stock solution concentration of $100 \mathrm{mg} / \mathrm{mL}$. The cytotoxicity of dyes was expressed as the half-maximal inhibitory concentration
$\left(\mathrm{IC}_{50}-\mathrm{mg} / \mathrm{mL}\right)$, where values higher than 1 represented low cytotoxicity, values within the range from 0.1 to 1 represented medium cytotoxicity, and values below 0.1 represented high cytotoxicity of samples [10]. Additionally, the cytotoxicity of the fungal liquid culture without precursors and products was checked as a control.

\section{Micellar electrokinetic chromatography (MEKC)}

MEKC analyses for optimisation of AHBS transformation by fungal biomass were performed on Thermo Capillary Electrophoresis, Crystal 100 (USA). The separations were carried out using fused silica capillary $(80 \mathrm{~cm}, 50 \mathrm{~cm}$ to detection window, inner diameter of $50 \hat{\mathrm{I}} 1 / 4 \mathrm{~m})$. The applied voltage was $29 \mathrm{kV}$, and the capillary temperature was maintained at $30^{\circ} \mathrm{C}$. Samples were injected hydrodynamically for $1 \mathrm{~s}$, and the detection was at $210 \mathrm{~nm}$. The buffer solution used was $100 \mathrm{mM}$ boric acid with $50 \mathrm{mM}$ dodecyltrimethylammonium bromide (TTAB), and the $\mathrm{pH}$ was adjusted to 9.3 using $\mathrm{NaOH}$. Liquid cultures after biotransformation by FF25 were prepared using MQwater and filtered through 0.22 syringe filters before use.

\section{Competing interests}

The authors declare that they have no competing interests.

\section{Authors' contributions}

JP and AJW designed the research; JP performed the cultivation and transformation experiments, analyzed the data and drafted the manuscript. AJW conceived of the study, and participated in its design and coordination and helped to draft the manuscript. All authors have read and approved the final version of the manuscript.

\section{Acknowledgements}

Project operated within the Foundation for Polish Science Ventures Programme co-financed by the EU European Regional Development Fund. The authors wish to thank Magali Foret and Robertus Onderwater from Wetlands Incubator sprl (BE) for toxicity tests.

\section{Author Details}

Department of Biochemistry, Maria Curie-Skłodowska University, Akademicka 19, Lublin, Poland

Received: 26 April 2010 Accepted: 5 July 2010

Published: 5 July 2010

References

1. Straathof AJ, Panke S, Schmid A: The production of fine chemicals by biotransformations. Curr Opin Biotechnol 2002, 13:548-556.

2. Thurston CF: The structure and function of fungal laccases. Microbiology 1994, 140:19-26.

3. Yaropolov Al, Skorobogatko OV, Vartanov SS, Varfolomeyev SD: Laccase: Properties, catalytic mechanism, and applicability. App/Biochem Biotechnol 1994, 49:257-280.

4. Setti L, Giuliani S, Spinozzi G, Pifferi PG: Laccase catalyzed oxidative coupling of 3-methyl 2-benzothiazolinone hydrazone and methoxyphenols. Enzyme Microb Technol 1999, 25:285-289.

5. Manda K, Hammer E, Mikolasch A, Niedermeyer T, Dec J, Daniel Jones A, Benesi AJ, Schauer F, Bollag JM: Laccase-induced cross-coupling of 4aminobenzoic acid with para-dihydroxylated compounds 2,5dihydroxy-N-(2-hydroxyethyl)-benzamide and 2,5-dihydroxybenzoic acid methyl esters. J Mol Catal B: Enzym 2005, 35:86-92.

6. Osiadacz J, Al-Adhami AJH, Bojraszewska D, Fischer P, Peczynska-Czoch W: On the use of Trametes versicolor lacase for the conversion of 4methyl-3-hydroxyanthranilic acid to actinocin chromophore. $J$ Biotechnol 1999, 72:141-149. 
7. Forte S, Polak J, Valensin D, Taddei M, Basosi R, Vanhulle S, JaroszWilkołazka A, Pogni R: Synthesis and structural characterization of a novel phenoxazinone dye by use of a fungal laccase. J Mol Catal B: Enzym 2010, 63:116-120.

8. Bruyneel F, Enaud E, Billottet L, Vanhulle S, Marchand-Bryaert J: Regioselective synthesis of 3-hydroxyorthanilic acid and its biotransformation into a novel phenoxazinone dye by use of laccase. Eur J Org Chem 2008, 1:72-79.

9. Bruyneel F, Jarosz-Wilkołazka A, Polak J, Bols Ch-M, Vanhulle S, Enaud E, Basosi R, Pogni R, Jager I, Hercher Ch, Marchand J: Phenoxazine dyes. US20100000032 2010

10. Enaud E, Trovaslet M, Bruyneel F, Billottet L, Karaaslan R, Sener ME, Coppens P, Casas A, Jaeger IJ, Hafner Ch, Onderwater RCA, Corbisier AM Marchand-Brynaert J, Vanhulle S: A novel azoanthraquinone dye made through innovative enzymatic process. Dyes Pigments 2010, 85:99-108.

11. Lang G, Cotteret J: Keratinous fibre oxidation dyeing composition containing a laccase and dyeing method using same. WO/1999/036040 1999.

12. Saettler $A$, Weiss $A$, Rose $D$, Kleen A: Colouring agents with enzymes. US663003B1 2003

13. Diaz Blanco CD, Diaz Gonzales M, Monmany JMD, Tzanov T: Dyeing properties, synthesis, isolation and characterization of an in situ generated phenolic pigment, covalently bound to cotton. Enzyme Microb Technol 2009, 44:380-385.

14. Calafell M, Diaz C, Hadziyska H, Gibert JM, Daga JM, Tzanov T: Biocatalyzed coloration of cellulose fibers. Biocatal Biotransform 2007 25:336-340.

15. Jonas U, Hammer E, Haupt ETK, Schauer F: Characterization of coupling products formed by biotransformations of biphenyl and biphenyl ether by the white rot fungus Pycnoporus cinnabarinus. Arch Microbiol 2000, 174:393-398.

16. Bartmańska A, Huszcza E, Tronina T: Transformation of isoxanthohumol by fungi. J Mol Catal B: Enzym 2009, 61:221-224.

17. Lamm AS, Chen ARM, Reynolds WF, Reese PB: Fungal hydroxylation of (-) - santonin and its analogues. J Mol Catal B: Enzym 2008, 59:292-296.

18. Siddiqui MF, Andleeb S, Ali N, Ghumro PB, Ahmed S: Up-flow immobilized fungal column reactor for the treatment of anthraquinone dye drimarene blue $\mathrm{K}_{2} \mathrm{RL}$. Afr J Biotechno/ 2009, 8:5570-5577.

19. Ramsay JA, Mok WHW, Luu YS, Savage M: Decoloration of textile dyes by alginate-immobilized Trametes versicolor. Chemosphere 2005, 61:956-964

20. Rodríguez Couto S, Sanromán MA, Hofer D, Gübitz GM: Stainless steel sponge: a novel carrier for the immobilisation of the white-rot fungus Trametes hirsuta for decolourization of textile dyes. Bioresour Technol 2004, 95:67-72.

21. Oestergaard LH, Wu G: Uses of laccase. WO2007054034 2007.

22. Hoeffkes H, Kleen A, Seattler A: Enzymatic dye. EP1239819 2002.

23. Xu F: Oxidation of phenols, anilines, and benzenethiols by fungal laccases: correlation between activity and redox potential as well as halide inhibition. Biochemistry 1996, 35:7608-7614

24. Chandra RP, Ragauskas AJ: Evaluating laccase-facilitated coupling of phenolic acids to high-yield kraft pulps. Enzyme Microb Techno/ 2002, 30:855-861

25. Bourbonnais R, Paice MG, Reid ID, Lanthier P, Yaguchi M: Lignin oxidation by laccase isozymes from Trametes versicolor and role of the mediator 2,2'-azinobis(3-ethylbenzthiazoline-6-sulfonate) in kraft lignin depolymerization. App/ Environ Microbiol 1995, 61:1876-1880.

26. Jarosz-Wilkołazka A, Graz M, Braha B, Menge S, Schlosser D, Krauss GJ: Species-specific $\mathrm{Cd}$-stress response in the white rot basidiomycetes Abortiporus biennis and Cerrena unicolor. Biometals 2006, 19:39-49.

27. Rogalski J, Leonowicz A: Microbial enzymes: production and applications. Laccase. In Concise encyclopedia of bioresource technology Edited by: Pandey A. Food Products Press; 2004

28. Neifar M, Jaouani A, Ellouze-Ghorbel R, Ellouze-Chaabouni S, Penninckx MJ: Effect of culturing processes and copper addition on laccase production by the white-rot fungus Fomes fomentarius MUCL 35117. Lett Appl Microbiol 2009, 49:73-8.

29. Eggert C, Temp U, Dean FD, Eriksson KE: Laccase-mediated formation of the phenoxazinone derivative, cinnabarinic acid. FEBS Lett 1995, 376:202-206.
30. Suzuki H, Furusho Y, Higashi T, Ohnishi Y, Horinouchi S: A novel oaminophenol oxidase responsible for formation of the phenoxazinone chromophore of Grixazone. J Biol Chem 2006, 281:824-833.

31. Ruan JW, Huang ZS, Huang JF, Du CJ, Huang SL, Shi Z, Fu LW, Gu CQ: Synthesis of phenoxazinone derivatives and antiproliferative activities on wild-type and drug-resistant tumor cells. Chin Chem Lett 2006, 17:1141-1144

32. Puiu M, Raducan A, Babaligea I, Oancea D: Oxidase-peroxidase reaction: kinetics of peroxidase-catalysed oxidation of 2-aminophenol. Bioprocess Biosyst Eng 2008, 31:579-586.

33. Alva KS, Kumar J, Marx KA, Tripathy SK: Enzymatic synthesis and characterization of a novel water-soluble polyaniline: poly $(2,5-$ diaminobenzenesulfonate). Macromolecules 1997, 30:4024-4029.

34. Patel BV, Dasoni PH: Studies on synthesis and dyeing preformance of acid dye based on 4,7-dihydroxy-3,8-di-a-naphtyl-azo-1,10phenanthroline-2,9-dione. E-J Chem 2007, 4:559-562.

35. Xu F, Berka RM, Wahleithner JA, Nelson BA, Shuster JR, Brown SH, Palmer $A E$, Solomon EJ: Site-directed mutations in fungal laccase: effect on redox potential, activity and pH profile. Biochem J 2004, 334:63-67.

36. Frasconi M, Favero G, Boer H, Koivula A, Mazzei F: Kinetic and biochemical properties of high and low redox potential laccases from fungal and plant origin. Biochim Biophys Acta 2010, 1804:899-908.

37. Bourbonnais R, Paice MG, Reid ID, Lanthier P, Yaguchi M: Lignin oxidation by laccase isozymes from Trametes versicolor and role of the mediator 2,2'-azinobis(3-ethylbenzthiazoline-6-sulfonate) in kraft lignin depolymerization. Appl Environ Microbiol 1995, 61:1876-1880.

38. Moreira Neto SL, Matheus DR, Gomes Machado KM: Influence of pH on the growth, laccase activity and RBBR decolourization by tropical basidiomycetes. Braz Arch Biol Tech 2009, 52:1075-1082.

39. Baldrian P: Fungal laccases - occurrence and properties. FEMS Microbiol Rev 2006, 30:215-242.

40. Wolfenden BS, Willson RL: Radical-cations as reference chromogens in kinetic studies of ono-electron transfer reactions: pulse radiolysis studies of 2,2'-azinobis-(3-ethylbenzthiazoline-6-sulphonate). J Chem Soc Perkin Trans 1982, 2:805-812.

doi: 10.1186/1475-2859-9-51

Cite this article as: Polak and Jarosz-Wilkocazka, Whole-cell fungal transformation of precursors into dyes Microbial Cell Factories 2010, 9:51

\section{Submit your next manuscript to BioMed Central and take full advantage of:}

- Convenient online submission

- Thorough peer review

- No space constraints or color figure charges

- Immediate publication on acceptance

- Inclusion in PubMed, CAS, Scopus and Google Scholar

- Research which is freely available for redistribution
C) BioMed Central 